Article

\title{
On the Importance of Halogen-Halogen Interactions in the Solid State of Fullerene Halides: A Combined Theoretical and Crystallographic Study
}

\author{
Antonio Bauzá and Antonio Frontera * \\ Department of Chemistry, Universitat de les Illes Balears, Crta de Valldemossa km 7.5, \\ 07122 Palma de Mallorca (Baleares), Spain; antonio.bauza@uib.es \\ * Correspondence: toni.frontera@uib.es; Tel.: +34-971-173426 \\ Academic Editors: Peter Politzer and Jane S. Murray \\ Received: 31 May 2017; Accepted: 22 June 2017; Published: 26 June 2017
}

\begin{abstract}
In this manuscript, we combined DFT (Density Functional Theory) calculations (BP86-D3/def2-TZVP level of theory) and a search in the CSD (Cambridge Structural Database) to analyze the role of halogen-halogen interactions in the crystal structure of fullerene halides. We have used a theoretical model of a halogenated $\mathrm{C}_{60}$ and evaluated the formation of halogen-halogen complexes between $\mathrm{F}, \mathrm{Cl}, \mathrm{Br}$ and I derivatives. In addition, we also carried out AIM (Atoms in Molecules) and NBO (Natural Bonding Orbital) analyses to further describe and characterize the interactions described herein. Finally, we have carried out a search in the CSD and found several $X$-ray structures where these interactions are present and important in governing the crystal packing of the fullerene halides, thus giving reliability to the results derived from the calculations.
\end{abstract}

Keywords: halogen-halogen interactions; CSD search; DFT calculations; AIM analysis

\section{Introduction}

The conjunction of a great deal of non-covalent forces is considered key for advances and progress in the field of Supramolecular chemistry [1,2]. Depth comprehension is crucial for chemists working in this discipline, since many chemical and biological processes are governed by an intricate combination of non-covalent interactions, forming the basis of highly specific recognition processes. For instance, interactions between hosts and guests dictate the formation of assemblies with high affinities, even in highly competitive media [3-6]. For this reason, a proper description and understanding of non-covalent interactions between molecules is key for success in this field of research. One of the classical and well-known supramolecular forces present in many chemical and biological environments is hydrogen bonding [7]. Similarly, halogen bonding [8] is a non-covalent force that shares strength and directionality features with hydrogen bonding. In particular, a halogen bond $(R-X \cdots Y-Z$, $\mathrm{X}=$ halogen, $\mathrm{Y}=$ electron-rich atom, $\mathrm{Z}=$ any atom) has been defined by the IUPAC as the "evidence of a net attractive interaction between an electrophilic region associated with a halogen atom in a molecular entity and a nucleophilic region in another, or the same, molecular entity" [9]. In this context, the ability of halogen atoms to interact with Lewis bases has been known for some time [10]. For instance, Resnati and colleagues have reported the ability of iodo- and bromo-perfluorocarbons to form non-covalent interactions with neutral and charged electron donors. In particular, they demonstrated the ability of halo-perfluoroalkanes to participate as halogen-bond donor moieties in crystal engineering, unveiling a promising potential of halogen bonding interactions in supramolecular chemistry [11-19]. Consequently, a series of studies using the Cambridge Structural Database (CSD) were carried out in order to shed light on the impact of this interaction in solid state chemistry [20,21]. Interest amongst the scientific community has expanded exponentially, due to the recognition of its 
importance in biological systems and the design of new materials, leading to a plethora of theoretical and experimental studies devoted to this fruitful line of research [22-25]. Apart from the classical halogen bond, there is growing interest amongst the scientific community to properly understand weaker halogen-halogen interactions [26], which have shown a promising future as stabilizing agents of metal complexes [27,28], by governing the formation of novel solid state architectures [29-31] and even tuning the properties of biological and conjugated materials [32-35]. In this regard, the presence of both an electron-rich "belt" and an electro-positive $\sigma$-hole ( $\mathrm{Cl}, \mathrm{Br}$ and I) are key to describe the two types of X ...X interactions, which are usually classified as either type I and II [36].

On the other hand, preparation of fullerene halides became available some time after the synthetic path of fullerenes was fully stablished. Research interest in the halogenation of fullerenes comes from a desire to expand the fundamentals of science, as well as from their key application as suitable synthons for further derivatization. In this context, halogenation has grown in importance among synthetic chemists during recent decades, due to the influence of the different addition patterns caused by different sizes of halogens. Consequently, halogenated fullerenes have been extensively studied as versatile and powerful synthons in fullerene chemistry. While iodination does not usually occur, other reactions with lighter halogens yield halogenated fullerenes under relatively mild conditions [37]. Concretely, one of the first to be investigated was the bromination of $\mathrm{C}_{60}$ in different organic solvents, yielding three fullerene bromides $[38,39]$. Related to this, the chlorination of $\mathrm{C}_{60}$ using iodine monochloride allowed the isolation of two fullerene chlorides, $\mathrm{C}_{60} \mathrm{Cl}_{6}$ [40] and $\mathrm{C}_{70} \mathrm{Cl}_{10}$ [41], characterized by NMR spectra. Finally, the fluorination of fullerenes using metal fluorides (among other fluorination agents) results in a wide range of adducts, from $\mathrm{C}_{60} \mathrm{~F}_{2}$ to $\mathrm{C}_{60} \mathrm{~F}_{48}$ [42-45]. Owing to their relatively high thermal stability, fluorofullerenes (contrary to chloro- and bromofullerenes) have been extensively investigated by electron impact (EI) mass spectrometry.

In this study, our goal was to analyze the energetic and stability properties of type I halogen-halogen interactions established between fullerene halides. For this purpose, we have used a reduced model of a halogenated $\mathrm{C}_{60}(\mathrm{~F}, \mathrm{Cl}, \mathrm{Br}$ and $\mathrm{I})$ in order to achieve a compromise between the level of theory and the size of the system. We have explored the formation of both homodimeric (complexes 5 to 8 in Figure 1) and heterodimeric (complexes 9 to 14 in Figure 1) systems. In addition, we have performed AIM (Atoms in Molecules) and NBO (Natural Bonding Orbital) analyses to further characterize the interactions described herein. Finally, we have performed a search in the CSD (Cambridge Structural Database) in order to find experimental evidence of the impact of halogen-halogen interactions on the solid state architectures of halogenated $\mathrm{C}_{60} \mathrm{~s}$.

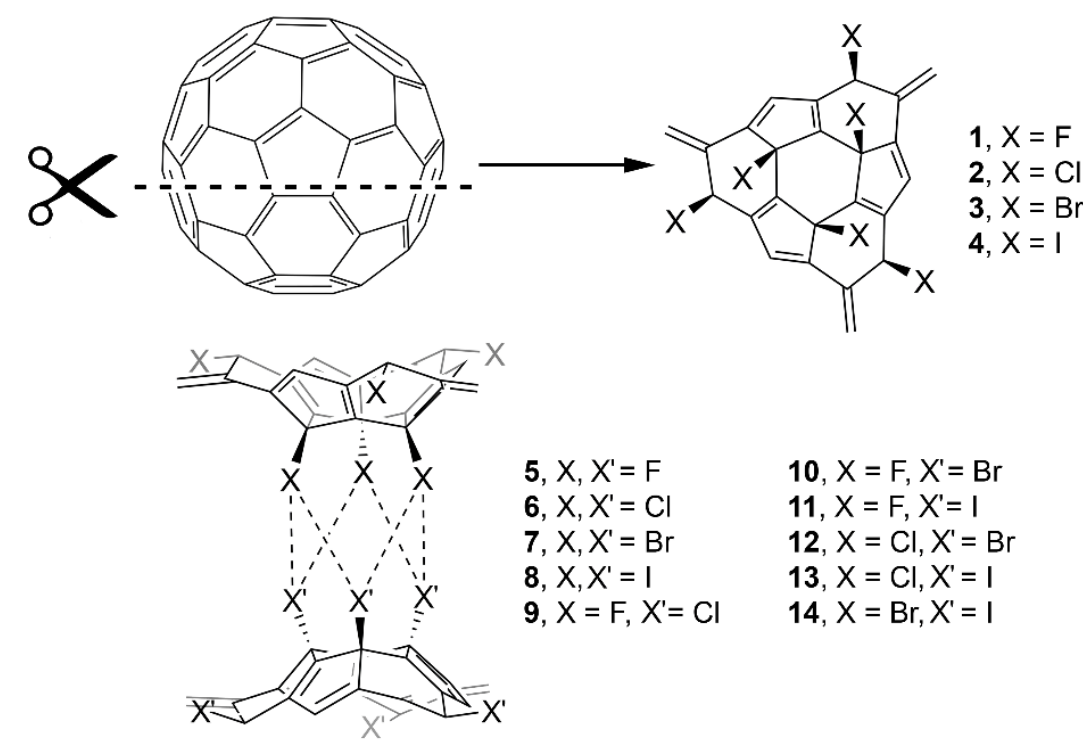

Figure 1. Compounds and complexes 1-14 studied in this work. 


\section{Results and Discussion}

\subsection{Preliminary MEP Analysis}

We have firstly computed the molecular electrostatic potential (MEP) mapped onto the van der Waals surface for compounds 1 to 4 (Figure 2). As noted, a positive electrostatic potential region is found on the extension of the $\mathrm{C}-\mathrm{X}$ bond for $\mathrm{Cl}, \mathrm{Br}$ and I derivatives (compounds 2, 3 and 4, respectively), named $\sigma$-hole. The presence of this region makes one expect an attractive interaction with an electron-rich entity. On the other hand, in the case of compound 1, the MEP value remained negative over the fluorine atom, thus leading us to expect a repulsive interaction with electron-rich species from an electrostatic point of view. The MEP values become more positive from F to I, as is known for halogen bonding interactions, resulting in an expectation of stronger binding energy values for complexes involving iodine than for the rest of halogens. Finally, it is also worth mentioning that the MEP value at the negative belt is almost the same for compounds 1 to 4 , a result that predicts a similar electron donor ability between them.

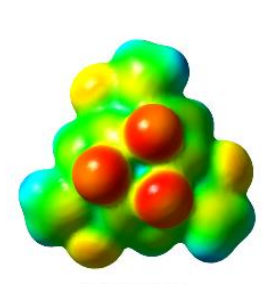

Top view

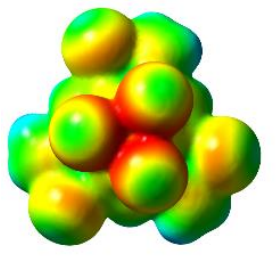

Top view

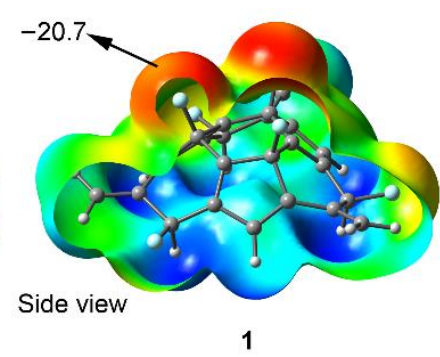

1

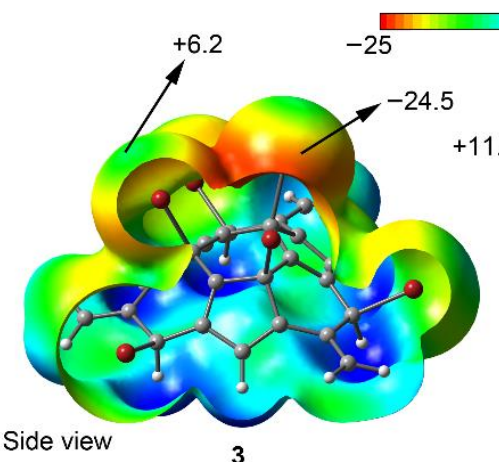

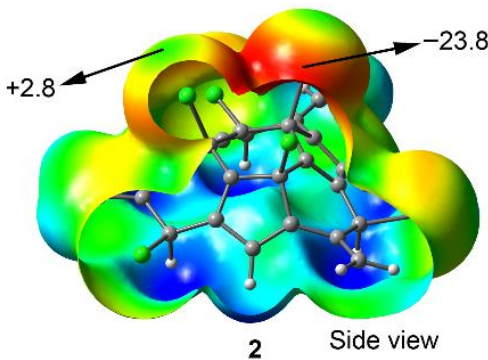

2

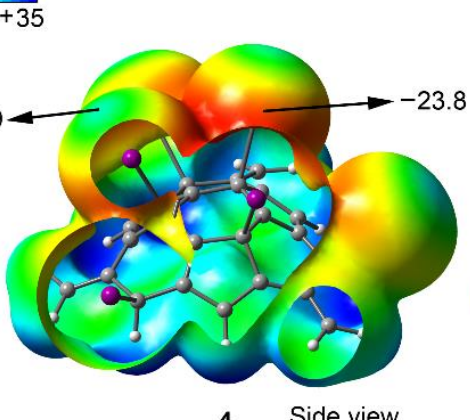

4 Side view

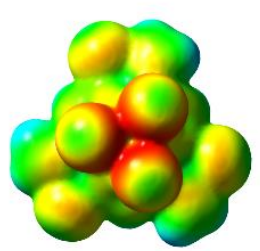

Top view

Figure 2. Molecular electrostatic potential (MEP) surfaces of compounds 1 to 4 used in the study. Energies at selected points of the surface (0.002 a.u.) are given in $\mathrm{kcal} / \mathrm{mol}$.

\subsection{Energetic and Geometric Results}

Table 1 gathers the interaction energies and equilibrium distances of optimized complexes 5 to 14 (see Figures 1 and 3), computed at the BP86-D3/def2-TZVP level of theory. From the analysis of these results, several points are worthy of discussion. First, in all complexes, the halogen moieties are dispersed in an "alternated" conformation. Thus, each halogen atom established a bifurcated halogen-halogen interaction with two neighboring atoms. This allows for the establishment of three halogen-halogen interactions in each dimer (see Figure 3). Second, for complexes 6 to 14, attractive and moderately strong interaction energy values were obtained, ranging between -12 and $-3.5 \mathrm{kcal} / \mathrm{mol}$. In particular, complex 8 involving I achieved the largest binding energy value of the study $(-11.7 \mathrm{kcal} / \mathrm{mol})$. On the other hand, for complex 5 involving F, a slightly repulsive interaction energy value was obtained $(+0.7 \mathrm{kcal} / \mathrm{mol})$, due to the absence of a positive $\sigma$-hole over the fluorine atoms, as shown in the MEP analysis. Since the MEP value over the fluorine atoms is large and negative (around $-20 \mathrm{kcal} / \mathrm{mol}$ ), other energetic terms, such as induction and dispersion contributions, compensate the unfavorable electrostatics of the interaction. Third, the binding energy values become 
more favorable as halogen combinations become heavier (see, for instance, complexes 5, 6, 7 and 8). This is due to a favorable increase in both electrostatics (shown in the MEP analysis) and in the polarization and dispersion terms, which become more prominent as the polarizability of the system does. In addition, when comparing both homo- and heterodimeric complexes, a remarkable gain in binding energy can be observed in the case of fluorine, with a strengthening of about $3 \mathrm{kcal} / \mathrm{mol}$ from

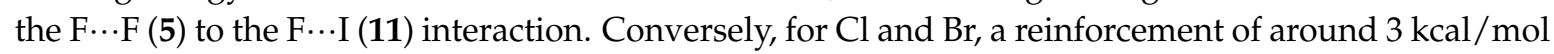
is observed from the homodimeric systems (complexes 6 and 7, respectively) to the heterodimers 12 and 14, where iodine is involved. Furthermore, in the case of I, the most favorable complex is the homodimer I $\cdots I$ (complex $8,-11.7 \mathrm{kcal} / \mathrm{mol}$ ), and any combination with another halogen atom results in a loss of interaction energy (see, for instance, complexes 13 and 14, -6.3 and $-8.6 \mathrm{kcal} / \mathrm{mol}$, respectively). Finally, in order to validate the results derived from the BP86-D3 method, we performed some additional complexes using the theoretical model shown in the bottom of Figure 3 and compared the DFT (Density Functional Theory) results with those obtained using the RI-MP2 method. As noted, in both cases, the interaction energy values are very similar, giving reliability to the BP86-D3 functional for dealing with these particular interactions.

Table 1. Interaction energies $(\triangle \mathrm{E}, \mathrm{kcal} / \mathrm{mol})$ and equilibrium distances $\left(\mathrm{R}_{1}\right.$ and $\left.\mathrm{R}_{2}, \AA\right)$, and value of the density at the bond critical point (CP) $\left(10^{2} \times \varrho\right.$, a.u.) for complexes 5-14 at the BP86-D3/def2-TZVP level of theory.

\begin{tabular}{ccccc}
\hline Complex & $\mathbf{\Delta E}$ & $\mathbf{R}_{\mathbf{1}}$ & $\mathbf{R}_{\mathbf{2}}$ & $\mathbf{1 0}^{\mathbf{2}} \mathbf{\times} \boldsymbol{\varrho}$ \\
\hline $\mathbf{5}(\mathrm{F} \cdots \mathrm{F})$ & +0.7 & 2.988 & 3.155 & 0.48 \\
$\mathbf{6}(\mathrm{Cl} \cdots \mathrm{Cl})$ & -3.5 & 3.661 & 3.787 & 0.49 \\
$\mathbf{7}(\mathrm{Br} \cdots \mathrm{Br})$ & -6.9 & 3.856 & 3.907 & 0.55 \\
$\mathbf{8}(\mathrm{I} \cdots \mathrm{I})$ & -11.7 & 4.068 & 4.175 & 0.67 \\
$\mathbf{9}(\mathrm{F} \cdots \mathrm{Cl})$ & -1.0 & 3.311 & 3.512 & 0.49 \\
$\mathbf{1 0}(\mathrm{F} \cdots \mathrm{Br})$ & -1.9 & 3.836 & 3.548 & 0.50 \\
$\mathbf{1 1}(\mathrm{F} \cdots \mathrm{I})$ & -3.0 & 3.504 & 3.630 & 0.59 \\
$\mathbf{1 2}(\mathrm{Cl} \cdots \mathrm{Br})$ & -5.0 & 3.747 & 3.851 & 0.53 \\
$\mathbf{1 3}(\mathrm{Cl} \cdots \mathrm{I})$ & -6.3 & 3.880 & 3.985 & 0.56 \\
$\mathbf{1 4}(\mathrm{Br} \cdots \mathrm{I})$ & -8.6 & 3.960 & 4.072 & 0.61 \\
\hline
\end{tabular}

\subsection{AIM and NBO Analyses}

We have used the Bader's theory of "atoms in molecules" [46] (AIM) to characterize the non-covalent interactions present in complexes 5-14. A bond critical point $(\mathrm{CP})$ and a bond path connecting two atoms is unambiguous evidence of interaction. The AIM distribution of critical points and bond paths computed for some complexes is shown in Figure 4. As noted, in all cases, two symmetrically distributed bond CPs connect the halogen atoms of both moieties, thus characterizing the bifurcated halogen-halogen interactions. In addition, six ring CPs emerged due to the formation of several supramolecular rings between the halogen atoms. Finally, a cage CP connecting both halogen moieties is also observed (shown as a green dot in Figure 4), further characterizing the interaction. It is also worth mentioning that no other bond paths and bond CPs were found during the analysis, meaning that halogen-halogen interactions are the only source of stabilization in these complexes. Finally, the value of the Laplacian in all cases is positive, as it is common in closed shell calculations.

In order to study the importance of orbital contributions in explaining the halogen-halogen complexes described above, we have performed Natural Bond Orbital (NBO) calculations focusing our attention on the second-order perturbation analysis, due to its usefulness in the analysis of donor-acceptor interactions [47]. The results are summarized in Table 2 and from the inspection of the results some interesting issues arise. First, for complexes 6 to 14, a common behavior is observed: that is, the main orbital contribution comes from the interaction between the lone pairs (LP) of the halogen atom to the antibonding $\left(\mathrm{BD}^{*}\right) \mathrm{C}-\mathrm{X}$ orbital. It is also important to mention that both monomers in complexes 6-14 participate as orbital donor and acceptor entities, with the only exception 
being complex 10, where only one orbital contribution from the lone pair (LP) of the $\mathrm{Br}$ atom to the antibonding $\left(\mathrm{BD}^{*}\right) \mathrm{C}-\mathrm{F}$ orbital is observed. In addition, the magnitude of the orbital contributions becomes larger from lighter (see complexes 6,9 and 10) to heavier halogen (for instance, complexes 7,12 and 13) systems, in agreement with the results derived from the energetic analysis discussed above. Keeping in mind that the orbital contribution is usually overestimated by the NBO method, the values gathered in Table 2 for the complexes involving the heavier halogens are not small compared to the total interaction energies (See Table 1), thus indicating that orbital effects are not negligible in these complexes.

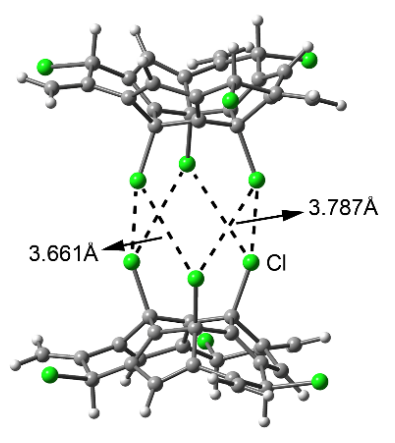

6

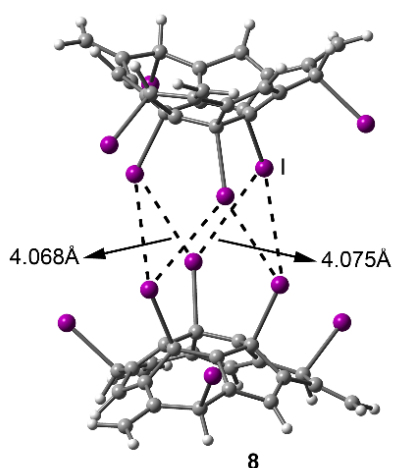

8

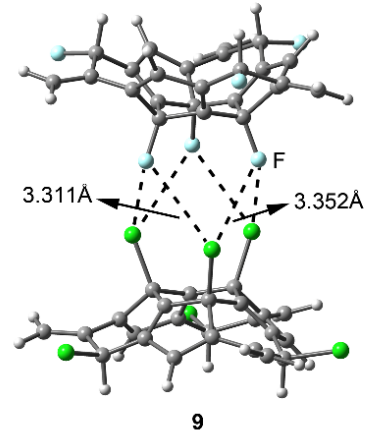

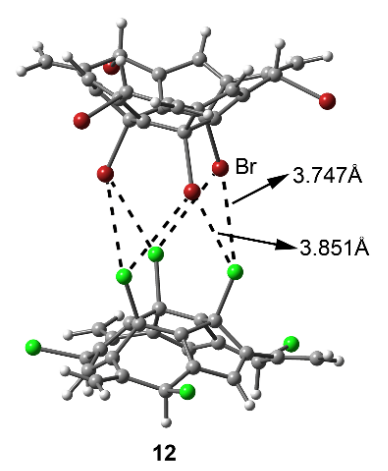
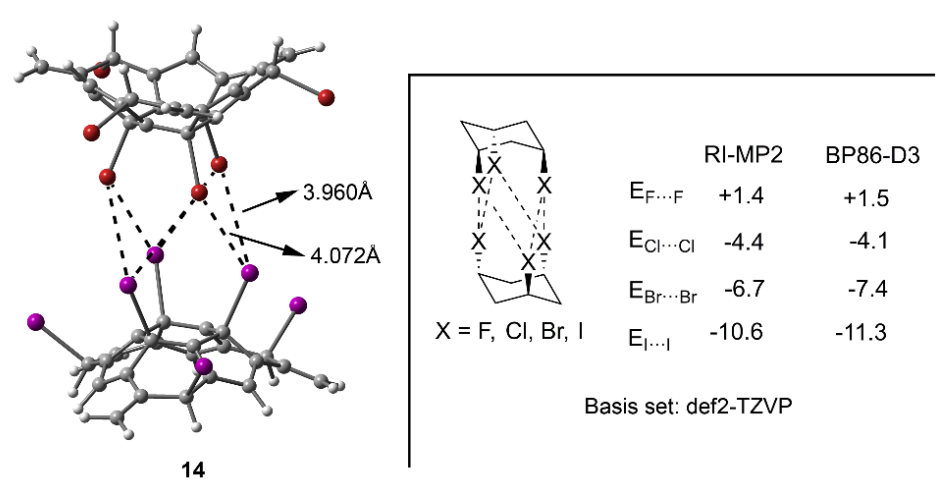

Figure 3. BP86-D3/def2-TZVP optimized geometries of some representative complexes. The theoretical models and basis set superposition error (BSSE) interaction energies using both RI-MP2 and BP86-D3 methods are also given.

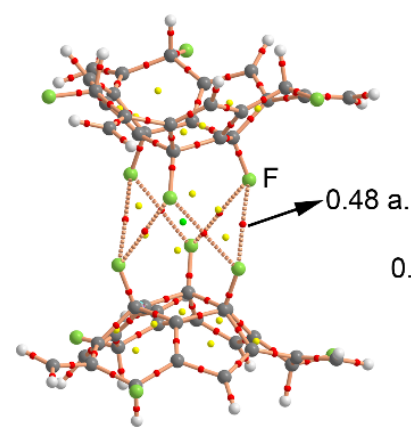

5

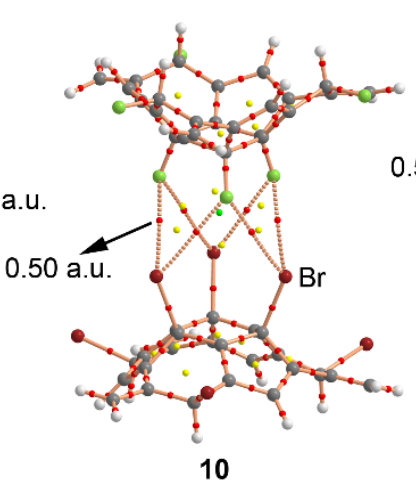

10

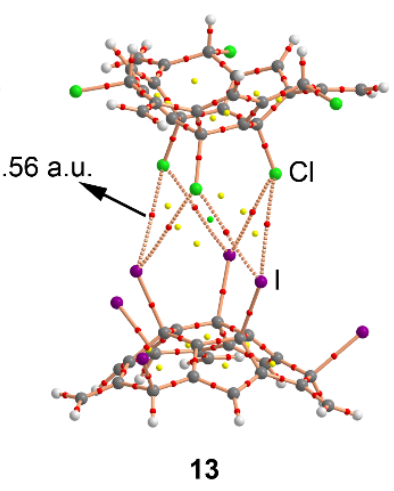

13

Figure 4. Distribution of critical points (red spheres) and bond paths for complexes $\mathbf{5 , 1 0}$ and $\mathbf{1 3}$ at the BP86/def2-TZVP level of theory. Bond, ring and cage CPs are represented by red, yellow and green spheres, respectively. The values of the charge density $(\varrho)$ at the bond critical points that emerge upon complexation are indicated in a.u. 
Table 2. Donor and acceptor natural bonding orbitals (NBOs) with an indication of the second-order interaction energy $\mathrm{E}^{(2)}(\mathrm{kcal} / \mathrm{mol})$ and type of interaction for complexes 5-14.

\begin{tabular}{cccc}
\hline Complex & Donor $^{\mathbf{a}}$ & Acceptor & $\mathbf{E}^{(\mathbf{2})}$ \\
\hline $\mathbf{5}$ & $-\mathrm{b}$ & $-^{\mathrm{b}}$ & $-^{\mathrm{b}}$ \\
$\mathbf{6}$ & $\mathrm{LP} \mathrm{Cl}$ & $\mathrm{BD}^{*} \mathrm{C}-\mathrm{Cl}$ & 1.50 \\
$\mathbf{7}$ & $\mathrm{LP} \mathrm{Br}$ & $\mathrm{BD}^{*} \mathrm{C}-\mathrm{Br}$ & 3.18 \\
$\mathbf{8}$ & $\mathrm{LP} \mathrm{I}$ & $\mathrm{BD}^{*} \mathrm{C}-\mathrm{I}$ & 5.88 \\
$\mathbf{9}$ & $\mathrm{LP} \mathrm{F}$ & $\mathrm{BD}^{*} \mathrm{C}-\mathrm{Cl}$ & 0.15 \\
$\mathbf{1 0}$ & $\mathrm{LP} \mathrm{Cl}$ & $\mathrm{BD}^{*} \mathrm{C}-\mathrm{F}$ & 0.27 \\
$\mathbf{1 1}$ & $\mathrm{LP} \mathrm{Br}$ & $\mathrm{BD}^{*} \mathrm{C}-\mathrm{F}$ & 0.54 \\
& $\mathrm{LP} \mathrm{F}$ & $\mathrm{BD}^{*} \mathrm{C}-\mathrm{I}$ & 0.39 \\
$\mathbf{1 2}$ & $\mathrm{LP} \mathrm{I}$ & $\mathrm{BD}^{*} \mathrm{C}-\mathrm{F}$ & 0.77 \\
& $\mathrm{LP} \mathrm{Cl}$ & $\mathrm{BD}^{*} \mathrm{C}-\mathrm{Br}$ & 2.40 \\
$\mathbf{1 3}$ & $\mathrm{LP} \mathrm{Br}$ & $\mathrm{BD}^{*} \mathrm{C}-\mathrm{Cl}$ & 1.05 \\
& $\mathrm{LP} \mathrm{Cl}$ & $\mathrm{BD}^{*} \mathrm{C}-\mathrm{I}$ & 1.35 \\
$\mathbf{1 4}$ & $\mathrm{LP} \mathrm{I}$ & $\mathrm{BD}^{*} \mathrm{C}-\mathrm{Cl}$ & 1.56 \\
& $\mathrm{LP} \mathrm{Br}$ & $\mathrm{BD}^{*} \mathrm{C}-\mathrm{I}$ & 1.95 \\
& $\mathrm{LP} \mathrm{I}$ & $\mathrm{BD}^{*} \mathrm{C}-\mathrm{Br}$ & 2.34
\end{tabular}

${ }^{\mathrm{a}} \mathrm{LP}, \overline{\mathrm{BD}^{*} \text { stand for lone pair and anti-bonding orbital, respectively, }{ }^{\mathrm{b}} \text { Nothing above threshold. }}$

\subsection{CSD Search}

We have explored the CSD to find evidence of the importance of halogen-halogen interactions in the crystal structures of halogenated fullerenes. We have found 127 fullerene halide structures, 32 of which correspond to $\mathrm{C}_{60}$ derivatives. Some relevant examples are shown in Figure 5. First, the crystal structure of IGOKEU $\left(\mathrm{C}_{60} \mathrm{~F}_{36}\right)$ [48], obtained by fluorination of $\mathrm{C}_{60}$ with $\mathrm{MnF}_{3} / \mathrm{K}_{2} \mathrm{NiF}_{6}$ at $480^{\circ} \mathrm{C}$, was characterized by both ${ }^{19} \mathrm{~F}$ NMR spectrum and single crystal X-ray analysis. In this structure, the large number of $\mathrm{sp}^{3}$ carbon atoms causes a deformation of the otherwise spherical $\mathrm{C}_{60}$. As noted, F...F interactions between fullerene units are key to stabilize its solid state architecture, thus governing the formation of the crystal packing. Second, the crystal structure of JUHJIF [39], obtained by reaction of $\mathrm{C}_{60}$ and liquid bromine at ambient temperatures, presents several $\mathrm{Br} \cdots \mathrm{Br}$ interactions involving neighboring $\mathrm{C}_{60}$ units. In this example, the $\mathrm{Br}$ atoms from the interacting regions of the two fullerene halides are dispersed in an "alternated" conformation, similar to the geometries retrieved from calculations. Third, in ELOWUY [49], a fullerene chlorobromide $\left(\mathrm{C}_{60} \mathrm{Cl}_{12} \mathrm{Br}_{12}\right)$ shows the presence of several $\mathrm{Cl} \cdots \mathrm{Br}$ interactions, which control the stability of the crystal packing. This is a good example that demonstrates the existence of "mixed" halogen-halogen interactions in fullerene derivatives. It is also worth pointing out that each fullerene halide is surrounded by seven neighboring units in IGOKEU and 12 in JUHJIF and ELOWUY structures, emphasizing the importance of these noncovalent forces as a stability source in the solid state.

Finally, the interaction energy values for some fullerene halide dimers were calculated (see Figure 5) and in all cases favorable and moderately strong values were obtained. The binding energy values lie within the range of the interactions described herein $(\sim 10 \mathrm{kcal} / \mathrm{mol})$ and the distances observed in the crystal structures are in agreement with those derived from calculations, thus giving reliability to the results retrieved from the theoretical models. In particular, the $\mathrm{Br} \cdots \mathrm{Br}$ interaction was shown to be more favorable than the $\mathrm{Cl} \cdots \mathrm{Br}$ interaction $(-11.8$ and $-10.6 \mathrm{kcal} / \mathrm{mol}$, respectively), in agreement with the energetic results discussed above (see complexes 7 and 12, respectively). On the other hand, in the case of the F...F interaction, the energy value obtained was larger than the that retrieved from calculations, owing to a large number of F...F interactions established and to the large polarizability of the fullerene moiety. 
a)
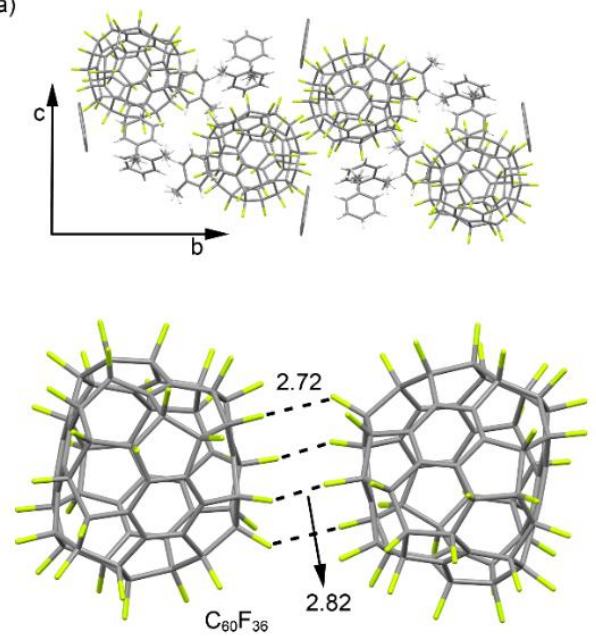

IGOKEU $\Delta \mathrm{E}_{\mathrm{F} \cdots \mathrm{F}}=-7.7 \mathrm{kcal} / \mathrm{mol}$ b)
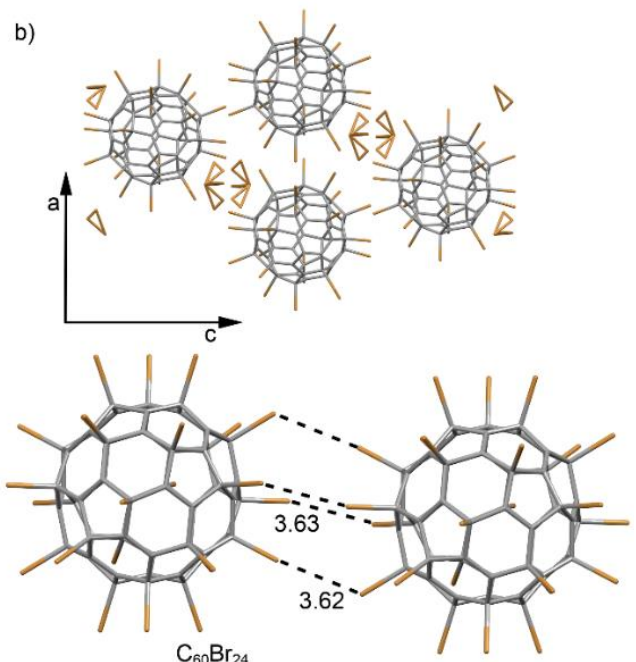

JUHJIF

$\Delta \mathrm{E}_{\mathrm{Br} \cdots \mathrm{Br}}=-11.8 \mathrm{kcal} / \mathrm{mol}$
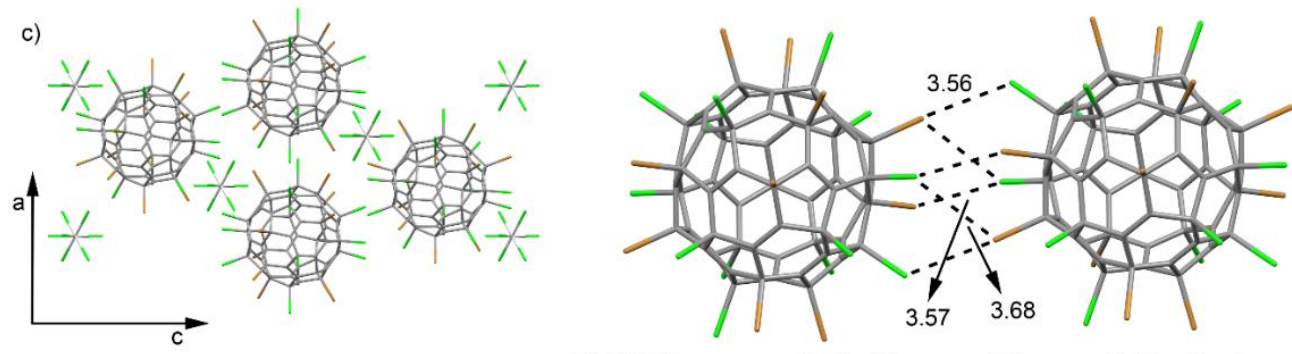

ELOWUY

Figure 5. Partial views of the $X$-ray structure of some fullerene halides (a) $\mathrm{C}_{60} \mathrm{~F}_{36}$, (b) $\mathrm{C}_{60} \mathrm{Br}_{24}$ and (c) $\mathrm{C}_{60} \mathrm{Br}_{12} \mathrm{Cl}_{12}$. Distances in angstroms. The Cambridge structural database (CSD) codes are also indicated.

\section{Theoretical Methods}

The geometries of the complexes studied herein have been fully optimized at the BP86-D3/def2-TZVP level of theory. The calculations have been performed by using the program TURBOMOLE version 7.0 [50]. We have used the BP86 functional with the latest available correction for dispersion (D3) [51]. The $C_{3}$ symmetry point group has been used in the optimization of the complexes. We have also computed the interaction energies for a series of halogenated cyclohexane molecules using both RI-MP2 and BP86-D3 methods as a validation tool. These interaction energies were calculated with correction for the basis set superposition error (BSSE) by using the Boys-Bernardi counterpoise [52]. For complexes 5 to 14, the BSSE correction was not applied. The MEP surfaces were plotted using an isovalue of 0.002 a.u. (99.4\% electron density). Bader's "Atoms in molecules" (AIM) theory has been used to study the interactions discussed herein by means of the AIMAll calculation package [53]. The NBO analysis was performed at the HF/def2-TZVP level of theory, by means of the Gaussian 09 calculation package [54]. Finally, single point calculations of IGOKEU, JUHJIF and ELOWUY X-ray structures were computed at the BP86-D3/def2-SVP level of theory.

\section{Conclusions}

In this manuscript, we have analyzed the impact of halogen-halogen interactions in the solid state of halogenated fullerenes. We have used a partial model of $\mathrm{C}_{60}$ and $\mathrm{F}, \mathrm{Cl}, \mathrm{Br}$ and $\mathrm{I}$ as halogen substituents. For all moieties, we have explored the formation of homo- and heterodimeric systems. The strength of the interaction ranges from slightly repulsive $(+0.7 \mathrm{kcal} / \mathrm{mol}$ for $\mathrm{F} \cdots \mathrm{F}$ interaction $)$ to moderately strong $(-11.7 \mathrm{kcal} / \mathrm{mol}$ for I $\cdots$ I interaction) and it becomes more favorable from lighter to 
heavier halogen combinations, due to an increase in both electrostatics and polarizability of the system. Moreover, we have performed AIM (Atoms in Molecules) and NBO (Natural Bonding Orbital) analyses to further describe and characterize the interactions presented herein. Finally, several experimental examples were retrieved from the CSD (Cambridge Structural Database) in order to give reliability to the results derived from calculations, and to highlight the importance of these interactions in the X-ray solid state structure of fullerene halides.

Supplementary Materials: The following are available online at http:/ /www.mdpi.com/2073-4352/7/7/191/s1, Cartesian coordinates of the complexes and results from the CSD search.

Acknowledgments: We thank the MINECO of Spain (project CTQ2014-57393-C2-1-P FEDER funds) for financial support. We thank the CTI for computational facilities.

Author Contributions: A.B. and A.F. conceived and designed the calculations; A.B. and A.F. analyzed the data; A.F. wrote the paper.

Conflicts of Interest: The authors declare no conflict of interest. The founding sponsors had no role in the design of the study; in the collection, analyses, or interpretation of data; in the writing of the manuscript, and in the decision to publish the results.

\section{Abbreviations}

The following abbreviations are used in this manuscript:

$\begin{array}{ll}\text { MDPI } & \text { Multidisciplinary Digital Publishing Institute } \\ \text { DOAJ } & \text { Directory of open access journals } \\ \text { DFT } & \text { Density Functional Theory } \\ \text { AIM } & \text { Atoms in molecules } \\ \text { MEP } & \text { Molecular electrostatic potential } \\ \text { MP2 } & \text { Second order Moller-Plesset } \\ \text { BSSE } & \text { Basis Set Superposition Error } \\ \text { CSD } & \text { Cambridge Structural Database } \\ \text { CP } & \text { Critical point } \\ \text { NBO } & \text { Natural Bond Orbital } \\ \text { MINECO } & \text { Ministerio de Economía y Competitividad }\end{array}$

\section{References}

1. Schneider, H.J. Binding mechanisms in supramolecular complexes. Angew. Chem. Int. Ed. 2009, 48, 3924-3977. [CrossRef] [PubMed]

2. Schneider, H.J.; Yatsimirski, A. Principles and Methods in Supramolecular Chemistry; Wiley: Chichester, UK, 2000.

3. Lehn, J.M. Supramolecular Chemistry Concepts and Perspectives; Wiley-VCH: Weinheim, Germany, 1995.

4. Vögtle, F. Supramolecular Chemistry: An Introduction; Wiley: New York, NY, USA, 1993.

5. Beer, P.D.; Gale, P.A.; Smith, D.K. Supramolecular Chemistry; Oxford University Press: Oxford, UK, 1999.

6. Steed, J.W.; Atwood, J.L. Supramolecular Chemistry; Wiley: Chichester, UK, 2000.

7. Grabowski, S.J. What is the covalency of hydrogen bonding? Chem. Rev. 2011, 111, 2597-2625. [CrossRef] [PubMed]

8. Metrangolo, P.; Resnati, G. Halogen bonding: A paradigm in supramolecular chemistry. Chem. Eur. J. 2001, 7, 2511-2519. [CrossRef]

9. Desiraju, G.R.; Ho, P.S.; Kloo, L.; Legon, A.C.; Marquardt, R.; Metrangolo, P.; Politzer, P.; Resnati, G.; Rissanen, K. Definition of the halogen bond (IUPAC Recommendations 2013). Pure Appl. Chem. 2013, 85, 1711-1713. [CrossRef]

10. Metrangolo, P.; Resnati, G. Halogen Bonding: Where we are and where we are going. Cryst. Growth Des. 2012, 12, 5835-5838. [CrossRef]

11. Metrangolo, P.; Neukirch, H.; Pilati, T.; Resnati, G. Halogen bonding based recognition processes: A world parallel to hydrogen bonding. Acc. Chem. Res. 2005, 38, 386-395. [CrossRef] [PubMed]

12. Metrangolo, P.; Resnati, G.; Pilati, T.; Biella, S. Halogen Bonding: Fundamentals and Applications; Springer: Berlin, Germany, 2008. 
13. Cavallo, G.; Metrangolo, P.; Milani, R.; Pilati, T.; Priimagi, A.; Resnati, G.; Terraneo, G. The halogen bond. Chem. Rev. 2016, 116, 2478-2601. [CrossRef] [PubMed]

14. Metrangolo, P.; Meyer, F.; Pilati, T.; Resnati, G.; Terraneo, G. Halogen bonding in supramolecular chemistry. Angew. Chem. Int. Ed. 2008, 47, 6114-6127. [CrossRef] [PubMed]

15. Bertani, R.; Metrangolo, P.; Moiana, A.; Perez, E.; Pilati, T.; Resnati, G.; Rico-Lattes, I.; Sassi, A. Supramolecular route to fluorinated coatings: Self-assembly between poly(4-vinylpyridines) and haloperfluorocarbons. Adv. Mater. 2002, 14, 1197-1201. [CrossRef]

16. Nguyen, H.L.; Horton, P.N.; Hursthouse, M.B.; Legon, A.C.; Bruce, D.W. Halogen bonding: A new interaction for liquid crystal formation. J. Am. Chem. Soc. 2003, 126, 16-17. [CrossRef] [PubMed]

17. Praesang, C.; Nguyen, H.L.; Horton, P.N.; Whitwood, A.C.; Bruce, D.W. Trimeric liquid crystals assembled using both hydrogen and halogen bonding. Chem. Commun. 2008, 6164-6166. [CrossRef] [PubMed]

18. Präsang, C.; Whitwood, A.C.; Bruce, D.W. Halogen-bonded cocrystals of 4-(N,N-Dimethylamino)pyridine with fluorinated iodobenzenes. Cryst. Growth Des. 2009, 9, 5319-5326. [CrossRef]

19. Roper, L.C.; Prasang, C.; Kozhevnikov, V.N.; Whitwood, A.C.; Karadakov, P.B.; Bruce, D.W. Experimental and theoretical study of halogen-bonded complexes of DMAP with Di- and triiodofluorobenzenes. A complex with a very short N...I halogen bond. Cryst. Growth Des. 2010, 10, 3710-3720. [CrossRef]

20. Murrayrust, P.; Motherwell, W.D.S. Computer retrieval and analysis of molecular geometry. 4. Intermolecular interactions. J. Am. Chem. Soc. 1979, 101, 4374-4376. [CrossRef]

21. Bauzá, A.; Quiñonero, D.; Deyà, P.M.; Frontera, A. Halogen bonding versus chalcogen and pnicogen bonding: A combined Cambridge structural database and theoretical study. CrystEngComm 2013, 15, 3137-3144. [CrossRef]

22. Brown, A.; Beer, P.D. Halogen bonding anion recognition. Chem. Commun. 2016, 52, 8645-8658. [CrossRef] [PubMed]

23. Politzer, P.; Murray, J.S. Halogen bonding: An interim discussion. ChemPhysChem 2013, 14, $278-294$. [CrossRef] [PubMed]

24. Politzer, P.; Murray, J.S.; Clark, T. Halogen bonding and other $\sigma$-hole interactions: A perspective. Phys. Chem. Phys. Chem. 2013, 15, 11178-11189. [CrossRef] [PubMed]

25. Bauzá, A.; Frontera, A. Supramolecular nanotubes based on halogen bonding interactions: Cooperativity and interaction with small guests. Phys. Chem. Chem. Phys. 2017, 19, 12936-12941. [CrossRef] [PubMed]

26. Awwadi, F.; Willett, R.; Peterson, K.; Twamley, B. The nature of halogen $\cdots$ halogen synthons: crystallographic and theoretical studies. Chem. Eur. J. 2006, 12, 8952-8960. [CrossRef] [PubMed]

27. Trokowski, R.; Akine, S.; Nabeshima, T. Remarkably selective recognition of iodobenzene derivatives by a macrocyclic bis-PtII metallohost. Chem. Eur. J. 2011, 17, 14420-14428. [CrossRef] [PubMed]

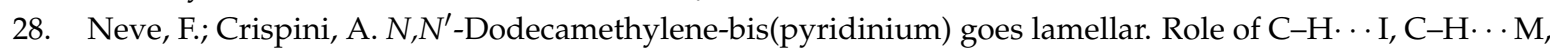
and I . . I interactions in the crystal structure of its hexaiododipalladate(II) derivative. CrystEngComm 2003, 5, 265-268. [CrossRef]

29. Felsmann, M.; Eissmann, F.; Schwarzer, A.; Weber, E. Competitive interactions in the crystal structures of benzils effected by different halogen substitution. Cryst. Growth Des. 2011, 11, 982-989. [CrossRef]

30. Saha, B.K.; Nangia, A.; Nicoud, J.F. Using halogen $\cdots$ halogen interactions to direct concentrosymmetric crystal packing in dipolar organic molecules. Cryst. Growth Des. 2006, 6, 1278-1281. [CrossRef]

31. Yamada, M.; Kanazawa, R.; Hamada, F. Halogen-halogen interactions and halogen bonding in thiacalixarene systems. CrystEngComm 2014, 16, 2605-2614. [CrossRef]

32. Baldrighi, M.; Bartesaghi, D.; Cavallo, G.; Chierotti, M.R.; Bogetto, R.; Metrangolo, P.; Pilati, T.; Resnati, G.; Terraneo, G. Polymorphs and co-crystals of haloprogin: an antifungal agent. CrystEngComm 2014, 16, 5897-5904. [CrossRef]

33. Ochoa, M.E.; Aguilar-Granda, A.; Ramirez-Montes, P.I.; Barba, V.; López, Y.; Santillan, R.; Farfán, N. Designed synthesis of "L" shaped 17-halo-aryl-ethynyl steroids. CrystEngComm 2016, 18, 6830-6840. [CrossRef]

34. Reddy, C.M.; Kirchner, M.T.; Gundakaram, R.C.; Padmanabhan, K.A.; Desiraju, G.R. Isostructurality, polymorphism and mechanical properties of some hexahalogenated benzenes: the nature of halogen $\cdots$ halogen interactions. Chem. Eur. J. 2006, 12, 2222-2234. [CrossRef] [PubMed]

35. Ahmed, F.; Roy, S.; Naskar, K.; Sinha, C.; Alam, S.M.; Kundu, S.; Vittal, J.J.; Mir, M.H. Halogen $\cdots$ halogen interactions in the supramolecular assembly of $2 \mathrm{D}$ coordination polymers and the $\mathrm{CO}_{2}$ sorption behavior. Cryst. Growth Des. 2016, 16, 5514-5519. [CrossRef] 
36. Mukherjee, A.; Desiraju, G.R. Halogen bonds in some dihalogenated phenols: applications to crystal engineering. IUCrJ 2014, 1, 49-60. [CrossRef] [PubMed]

37. Taylor, R. Lecture Notes on Fullerene Chemistry, Imper; College Press: London, UK, 1999; p. 268.

38. Birkett, P.R.; Hitchcock, P.B.; Kroto, H.W.; Taylor, R.; Walton, D.R.M. Preparation and characterization of $\mathrm{C}_{60} \mathrm{Br}_{6}$ and $\mathrm{C}_{60} \mathrm{Br}_{8}$. Nature 1992, 357, 479-481. [CrossRef]

39. Tebbe, F.N.; Harlow, R.L.; Chase, D.B.; Thorn, D.L.; Campbell, G.C.; Calabrese, J.C.; Herron, N.; Young, R.J.; Wasserman, E. Synthesis and single-crystal X-ray structure of a highly symmetrical $\mathrm{C}_{60}$ derivative, $\mathrm{C}_{60} \mathrm{Br}_{24}$. Science 1992, 256, 822-825. [CrossRef] [PubMed]

40. Birkett, P.R.; Avent, A.G.; Darwish, A.D.; Kroto, H.W.; Taylor, R.; Walton, D.R.M. Preparation and ${ }^{13}$ C NMR spectroscopic characterization of $\mathrm{C}_{60} \mathrm{Cl}_{6}$. J. Chem. Soc. Chem. Commun. 1993, 1230-1232. [CrossRef]

41. Birkett, P.R.; Avent, A.G.; Darwish, A.D.; Kroto, H.W.; Taylor, R.; Walton, D.R.M. Formation and characterization of $\mathrm{C}_{70} \mathrm{Cl}_{10}$. J. Chem. Soc. Chem. Commun. 1995, 683-684. [CrossRef]

42. Taylor, R. Progress in fullerene fluorination. Russ. Chem. Bull. 1998, 47, 823-832. [CrossRef]

43. Taylor, R. Fluorinated fullerenes. Chem. Eur. J. 2001, 7, 4074-4083. [CrossRef]

44. Boltalina, O.V. Fluorination of Fullerenes and their derivatives. J. Fluorine Chem. 2000, 101, $273-278$. [CrossRef]

45. Sidorov, L.N.; Boltalina, O.V. Endohedral metal derivatives and exohedral fluorine derivatives of fullerenes. Russ. Chem. Rev. 2002, 71, 535-561. [CrossRef]

46. Bader, R.F.W. A quantum theory of molecular structure and its applications. Chem. Rev. 1991, 91, 893-928. [CrossRef]

47. Weinhold, F.; Landis, C.R. Valency and Bonding: A Natural Bond Orbital Donor-Acceptor Perspective; Cambridge University Press: Cambridge, UK, 2005.

48. Avent, A.G.; Clare, B.W.; Hitchcock, P.B.; Kepert, D.L.; Taylor, R. $\mathrm{C}_{60} \mathrm{~F}_{36}$ : There is a third isomer and it has $\mathrm{C} 1$ symmetry. Chem. Commun. 2002, 2370-2371. [CrossRef]

49. Troyanov, S.I.; Burtsev, A.V.; Kemnitz, E. Synthesis and structure of fullerene halides in the $\mathrm{C}_{60}-\left(\mathrm{TiCl}_{4}+\mathrm{Br}_{2}\right)$ system: Molecular structures of $\left(\mathrm{C}_{60} \mathrm{Cl}_{5}\right)_{2}, \mathrm{C}_{60} \mathrm{X}_{6}, \mathrm{C}_{60} \mathrm{X}_{8}$, and $\mathrm{C}_{60} \mathrm{X}_{24}(\mathrm{X}=\mathrm{Cl}, \mathrm{Br})$. Kristallografiya 2009, 54, 268-275. [CrossRef]

50. Ahlrichs, R.; Bär, M.; Hacer, M.; Horn, H.; Kömel, C. Electronic structure calculations on workstation computers: The program system Turbomole. Chem. Phys. Lett. 1989, 162, 165-169. [CrossRef]

51. Grimme, S.; Antony, J.; Ehrlich, S.; Krieg, H. A consistent and accurate ab initio parametrization of density functional dispersion correction (DFT-D) for the 94 elements H-Pu. J. Chem. Phys. 2010, 132, 154104. [CrossRef] [PubMed]

52. Boys, S.B.; Bernardi, F. The calculation of small molecular interactions by the differences of separate total energies. Some procedures with reduced errors. Mol. Phys. 1970, 19, 553-566.

53. AIMAll. Version 13.05.06. TK Gristmill Software: Overland Park, KS, USA, 2013.

54. Frisch, M.J.; Trucks, G.W.; Schlegel, H.B.; Scuseria, G.E.; Robb, M.A.; Cheeseman, J.R.; Scalmani, G.; Barone, V.; Petersson, G.A.; Nakatsuji, H.; et al. Gaussian 09, Revision B.01; Guassian Inc.: Wallingford, CT, USA, 2009.

(C) 2017 by the authors. Licensee MDPI, Basel, Switzerland. This article is an open access article distributed under the terms and conditions of the Creative Commons Attribution (CC BY) license (http:/ / creativecommons.org/licenses/by/4.0/). 